\title{
Modelling the effect of marine protected areas on the population of skipjack tuna in the Indian Ocean
}

\author{
Sibylle DUERI and Olivier MAURY ${ }^{\mathrm{a}}$ \\ Institut de Recherche pour le Développement (IRD), UMR EME 212 (IRD/Ifremer/Université Montpellier 2), Centre de recherche halieutique \\ méditerranéenne et tropicale, av. Jean Monnet, BP 171, 34203 Sète Cedex, France
}

Received 14 May 2012; Accepted 8 October 2012

\begin{abstract}
The benefits of implementing no-take Marine Protected Areas (MPAs) for the conservation of highly migratory species are not easy to assess. They depend on several factors, such as the fish mobility, fisher behaviour and the area covered by the MPA with respect to the distribution area of the species to protect. In this study, we explore the simultaneous effects of MPAs and fishing scenarios on skipjack tuna population dynamics, using the spatially-explicit APECOSM-E model. The model represents the size-structured population dynamics of skipjack tuna in the Indian Ocean and their dependence on climatic variability and exploitation by fisheries. Numerical experiments were run from the beginning of industrial fisheries in the early 1980s to the year 2030, considering different scenarios for the future development of fisheries. These scenarios combined different trends in fishing effort and technological development, either assuming a continuous increase following historical trends or a stabilization of these factors at present values. The simulations were designed to explore the effects of two MPAs of different size and location: the recently established Chagos MPA, and a hypothetical MPA covering a large part of the Western Indian Ocean, where most of the skipjack catches are presently made. We modelled the redistribution of fishing effort around the MPAs assuming that the fishers had partial knowledge of the spatial distribution of the skipjack population. The effects of the two MPAs on the population dynamics, catch and fishing mortality are shown. Our results revealed a very minor effect of the Chagos MPA on the skipjack tuna population, while the Western Indian Ocean MPA had an important impact on the fishing mortality and succeeded in stabilizing the spawning population. The simulations also showed that the effect of an MPA depends on the evolution of fisheries and it is therefore important to explore different fishery scenarios to assess the future benefits of an MPA.
\end{abstract}

Keywords: Marine reserves / Fishery scenarios / Fishery management / Tropical tuna / Katsuwonus pelamis / Chagos MPA

\section{Introduction}

Skipjack tuna (Katsuwonus pelamis) is a widely distributed pelagic fish commonly found in tropical waters and commercially caught by industrial and artisanal surface fisheries. Skipjack tuna does not follow clear spawning or feeding migration patterns (Stéquert and Ramcharrun 1996) but rather exhibits home range movements within habitat preferences. The spatial distribution, movements and catchability of skipjack tuna are affected by environmental conditions, such as prey availability, temperature and dissolved oxygen concentration (Barkley et al. 1978; Brill 1994; Brill and Lutcavage 2001). As a consequence, the basin-scale spatial distribution of fishing effort on skipjack shows seasonal and interannual patterns that can be related to environmental conditions (Mugo et al. 2010).

The Indian Ocean has a long tradition of artisanal skipjack fishing that has been practiced for several centuries (Marine Research Section 1996). Since the early 1980s, catches have

\footnotetext{
${ }^{\text {a }}$ Corresponding author: sibylle.dueri@ird.fr
}

considerably increased due to the development of industrial purse seining and the concurrent rise of bait boat and gillnet catches. At present, the catches of skipjack tuna represent almost half of the total catch of tropical tuna in the Indian Ocean. Although the skipjack population is considered to have a high resilience against overfishing, due to fast growth rate and the year round spawning, the decreasing trend of surface fisheries catches since 2006 led to concerns about the sustainability of the present level of exploitation (Adam 2010, IOTC 2010a). The recent development of Somalian piracy, which led to a decline of the nominal effort along the usually well exploited Somalian coast (UNOSAT 2009), could partially explain the observed decrease in catches. Nevertheless, other fisheries such as the Maldivian bait boat fleet, which exploits a fishing ground located around the Maldives that does not overlap with the area of pirate attacks, have also reported a decrease in catch (Adam 2010). This trend of decreasing catches could be a symptom of overfishing and further investigations are needed to clarify its causes. 
The design of no-take Marine Protected Areas (MPAs) to improve the conservation and rebuilding of marine ecosystems and to protect stocks against overfishing has received increasing attention during recent decades (Sumaila et al. 2000; Pitcher 2001). The positive effects of marine reserves have been documented for many species, both within the boundaries of the reserves (Lester et al. 2009) and in terms of increased catch rates for the adjacent fisheries (Roberts et al. 2001, 2005). Modelling studies have shown the crucial importance of considering larval dispersion and adult migration processes when assessing the benefits of MPAs, and have highlighted that the MPA size should be significantly larger than the home range of a species in order to be effective for conservation (Walters et al. 2007; Moffit et al. 2009; Grüss et al. 2011). Moreover, the redistribution of fishing effort around MPAs needs to be considered since it can significantly affect their conservation potential and efficiency (Wilcox and Pomeroy 2003).

Most MPAs are currently located in coastal ecosystems and target the protection of species with high site fidelity and limited mobility. Pelagic MPAs are expected to extend conservation to highly migratory species by protecting sensitive habitats such as feeding and spawning grounds (Hyrenbach et al. 2000; Game et al. 2009). However, the benefits of the implementation of MPAs for highly mobile species are difficult to assess and depend on several factors, such as fish movements, fisher behaviour and the area covered by the MPA with respect to the distribution area (Walters 2000; Wilen et al. 2002).

The movement patterns and distribution of migrating species are driven by the seasonally changing conditions of the oceanic ecosystem. Pelagic MPAs with dynamic boundaries are highly flexible tools that allow the dynamics of the targeted species to be tracked (Hyrenbach et al. 2000). Although real-time dynamic spatial management has been implemented for southern bluefin tuna in Eastern Australian waters, based on the matching of fish temperature preferences with sea surface temperature and vertical temperature data from an oceanographic model (Hobday and Hartmann 2006; Hobday et al. 2011), the implementation of large scale dynamic MPAs in pelagic ecosystems still represents a real challenge for governance (Game et al. 2009).

Skipjack tuna does not show a preferred and recurrent spawning or feeding ground, making the implementation of an MPA for this species challenging. The extensive markrecapture program carried out in the Indian Ocean has revealed rapid and large scale movements of skipjack tuna, higher than in other oceans, with fish achieving distances of 500 to 1000 nautical miles in less than 3 months (IOTC 2008). Furthermore, in the Indian Ocean, the high seasonal and interannual variability of the oceanographic conditions drives the spatial pattern of catches by affecting the habitat quality and accessibility of the tuna (Marsac and Le Blanc 1998; Ménard et al. 2007). The rapid and large scale movements of skipjack tuna, combined with the environmental variability that affects the accessibility of the resource, are further issues to be considered in the design of MPAs in the Indian Ocean.

In the Indian Ocean, two large pelagic areas have been recently declared as MPAs. The first one is a no-take zone covering a surface of $650000 \mathrm{~km}^{2}$ around the Chagos Archipelago, which was designed by the British Government in 2010. The second one is a 1-month closure of a large zone east of Somalia to purse seine and longline fishing (IOTC 2010b). Koldewey et al. (2010) suggested that the implementation of the Chagos no-take MPA could benefit not only coralreef-dwelling species, but also large pelagic migratory species such as tropical tunas. They claimed that the "island mass effect" is responsible for an increased oceanic productivity that would attract tropical tuna to around the islands and retain them for a significant amount of time. However, up until now, the conservation potential of the Chagos MPA for highly migratory species has not been proved by data analysis or modelling studies.

In this paper, we present the use of a size-structured and spatially-explicit population dynamics model to investigate the impact of pelagic no-take MPAs, including the Chagos MPA, on the Indian Ocean skipjack tuna population. We assessed the effects of MPAs in terms of future trends of spawning population biomass, catch and mortality for MPAs of different size and location and consider the effects of different future developments in the skipjack fisheries. The objective was to explore the combined effect of the MPAs and fishery scenarios on the conservation of the population.

\section{Methodology}

\subsection{The APECOSM-E model}

APECOSM-E (Apex-Predator-Ecosystem-Model - Estimation) is a numerical model that represents basin-scale population dynamics of tropical tuna under the joint effects of environmental conditions and exploitation by fisheries (for a detailed description of the model see Dueri et al. 2012a). APECOSM-E is derived from the global multi-species APECOSM model (Maury 2010) but, unlike APECOSM, it considers only a single species of top predator (i.e., skipjack tuna).

The present study builds upon a previous application of APECOSM-E, in which the model was optimized to represent the population dynamics of skipjack tuna in the Indian Ocean (Dueri et al. 2012a). In that study, parameters were estimated by minimizing a cost function that combined the negative log-likelihoods of catches and size frequencies of commercial fleets, using a Bayesian term (Dueri et al. 2012b). The Bayesian component accounted for the difference between the initial values of the parameters and the new values, assuming that the a priori distribution of parameters was normal.

The APECOSM-E model is particularly appropriate for representing the effects of MPAs, since it is spatially explicit, considers the movement of fishes due to habitat gradients and accounts for the spatial dynamics of the fisheries. The model is structured in three spatial dimensions $(x, y, z)$, includes fish size (structural volume $V\left[\mathrm{~m}^{3}\right]$ ), and considers size-dependent reproduction, growth, predation, natural mortality and fishing mortality. It is based on a single partial differential equation describing the change in the biomass density function $p\left[\mathrm{~kg} \mathrm{~m}^{-3} \mathrm{~m}^{-3}\right]$ of the population as a function of time:

$$
\partial_{t} p=\operatorname{div}(d v p-v p)+\partial_{z}\left(d_{z} \partial_{z} p-v_{z} p\right)-\partial_{V}(g p)-(m+f) p
$$


in $\Omega \times\left(V_{b}, V_{\max }\right) \times\left(0, t_{\max }\right)$, where $\Omega$ is a bounded domain representing the Indian Ocean in three dimensions, $V_{b}$ and $V_{\max }$ represent the structural volume at birth and the maximal structural volume, respectively, and $t_{\max }$ is the maximum simulated time. The left-hand term of Eq. (1) is the time-derivative of the biomass density function and the four terms on the right-hand side represent: 1) horizontal advection and diffusion, 2) vertical advection and diffusion, 3) growth and 4) natural and fishing mortality. Advection and diffusion are constrained by the horizontal velocity $v(x, y, z, V, t)\left[\mathrm{m} \mathrm{s}^{-1}\right]$, the vertical velocity $v_{z}(x, y, z, V, t)\left[\mathrm{m} \mathrm{s}^{-1}\right]$, the horizontal diffusion $d(x, y, z, V, t)\left[\mathrm{m}^{2} \mathrm{~s}^{-1}\right]$ and the vertical diffusion $d_{z}(x, y, z, V, t)$ $\left[\mathrm{m}^{2} \mathrm{~s}^{-1}\right]$. Growth is represented as an advection of the biomass density along the size dimension and is defined by the growth rate $g(x, y, z, V, t)\left[\mathrm{m}^{3} \mathrm{~s}^{-1}\right]$, while natural and fishing mortality rates are described by $m(x, y, z, V, t)\left[\mathrm{s}^{-1}\right]$ and $f(x, y, z, V, t)$ $\left[\mathrm{s}^{-1}\right]$, respectively. The model is integrated numerically on a $1^{\circ}$ by $1^{\circ}$ horizontal grid covering the Indian Ocean and 20 vertical layers reaching $500 \mathrm{~m}$ depth, with a $10 \mathrm{~m}$ interval over the first $150 \mathrm{~m}$. The equations used to represent the terms $v, v_{z}$, $d, d_{z}, g, m$ and $r$ and the values of the model parameters after optimization are given in Dueri et al. (2012a,b).

Processes are all time-, space- and size-dependent and linked to the environment through mechanistic bioenergetic or behavioural parameterizations. The model uses threedimensional fields of temperature, oxygen and food, provided by the coupled bio-physical model NEMO-PISCES (Aumont and Bopp 2006) to define the three-dimensional habitat function that determines the active movements of tuna. Horizontal movements are modelled using the partial differential equations derived by Faugeras and Maury (2007), which provide a mechanistic representation of the advection and diffusion coefficients as well as a link between these coefficients. Passive horizontal movements are driven by oceanographic currents and physical diffusion. Physiological rates such as growth, reproduction and ageing mortality are described consistently with the Dynamic Energy Budget (DEB) theory (Kooijman 2000) and depend on temperature and food conditions. Spatially-explicit fishing effort is applied to the simulated biomass to compute catches and size frequencies and determine fishing mortality using size and depth-dependent selectivity functions.

\subsection{Modelling fishing mortality and the redistribution of fishing effort}

The model represents fishing mortality as the product of the spatial fishing effort $e$ and the catchability $p$ at time $t_{0}$, multiplied by an exponential function representing the increase in fishing efficiency at a rate $a$ due to technological development over time, and two sigmoidal selectivity functions, one for length 1 and the other for depth $z$.

$$
\begin{aligned}
f(x, y, z, V, t)= & e(x, y, t) p \exp (a t) \frac{1}{1+\exp \left(-k_{l}\left(\frac{V^{1 / 3}}{\partial_{M}}-l_{S}\right)\right)} \\
& \times \frac{1}{1+\exp \left(k_{z}\left(z-z_{s}\right)\right)} .
\end{aligned}
$$

Technological improvements include the increase of the size and performance of the fishing vessels, the increasing efficiency of the fishing gears, increasing performances of electronic devices such as bird radar, sonar and remote sensing tools and the deployment of increasingly sophisticated fish aggregating devices (FADs) (Valdemarsen 2001). The term $\frac{V^{1 / 3}}{\partial_{M}}$ represents the length of the fish, expressed in DEB notation as a function of the volume $V\left[\mathrm{~m}^{3}\right]$ and the shape coefficient $\partial_{M}[-]$. The length and depth selectivity are represented using sigmoid functions where $l_{S}$ and $z_{S}$ are the length and depth leading to $50 \%$ selection while $k_{l}$ and $k_{z}$ characterise the steepness of the sigmoid curves.

In this version of APECOSM-E, the spatial distribution of fishing effort is modelled dynamically, considering that the vessel captains have partial knowledge of the distribution of the skipjack tuna biomass in the ocean, following the approach proposed by Maury and Gascuel (1999). Each month, the model allocates a unit of fishing effort to a given number of $1^{\circ} \times 1^{\circ}$ cells. The cell where the effort is applied is determined by randomly drawing a fraction $\alpha[0,1]$ of the total number of cells and attributing the effort to the cell with the highest fishable biomass. When simulating the redistribution of effort around the MPA, the same procedure is followed but the cells inside the MPA are excluded from the drawing process. This approach does not consider travel time and distance between the home ports of the vessels and the selected cell or travel distance from one cell to another.

\subsection{Fishery data}

In order to determine the impact of fisheries on the skipjack population, we needed to set the parameters that define fishing mortality (Eq. (2)), such as the fishing power, the strength of the fishing effort and the number of $1^{\circ} \times 1^{\circ}$ cells where fishing effort is applied, as well as their temporal trend. Given the large scale and the complexity of the system, several simplifying assumptions were introduced. The simulations considered a single fleet composed of vessels having the same fishing power and experiencing the same technological improvement. The linear trend used to describe the evolution of the effort and number of exploited cells were extrapolated from the data reported for purse seiners with fleet codes "France", "Spain", "Mauritius", "Seychelles" and "Not elsewhere included-other" (NEI-other). The dataset of catch and effort, covering the period 1984 to 2006 on a $1^{\circ} \times 1^{\circ}$ grid, was obtained from the Indian Ocean Tuna Commission in the standardized form which is available on the CLIOTOP MDST website (http:// vmmdst-proto.mpl.ird.fr/MDST/).

A linear regression was applied to the average number of monthly-fished $1^{\circ} \times 1^{\circ}$ cells as well as to the yearly fishing effort, expressed as the sum of the fishing days reported by all fleets over a year (Fig. 1). Fishing power was set at 0.0165 in accordance with results from parameter estimation from a previous study (Dueri et al. 2012b). The parameter describing the increase due to technological development was set at 0.1 for the period 1984 to 1993 and 0.05 for the period 1994-2010, based on reported trends of tuna catchability (Maury and Nordström 2002). 

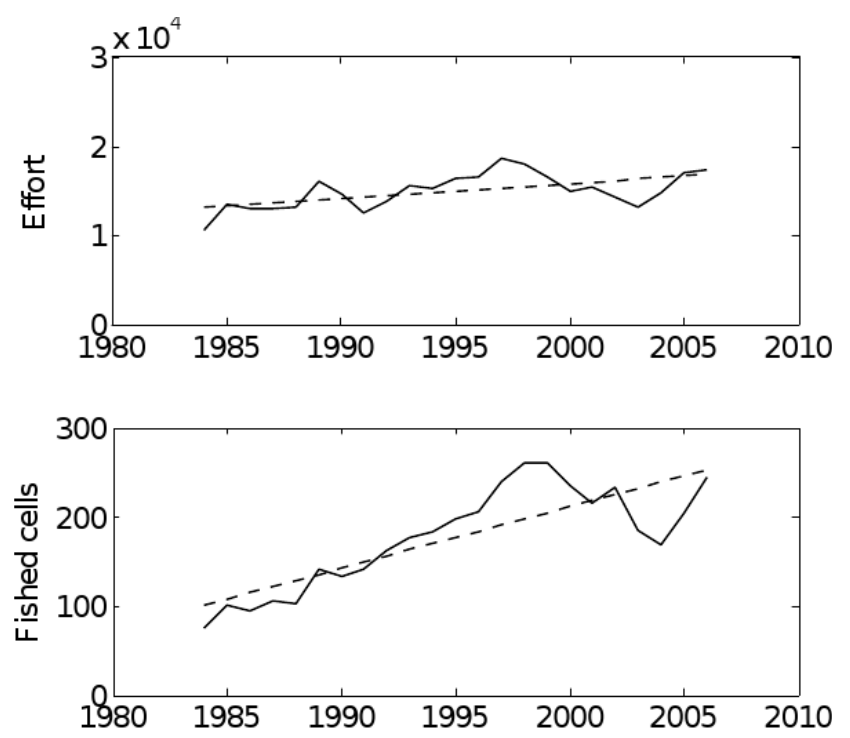

Fig. 1. Total yearly fishing effort (top) and average number of monthly-fished $1^{\circ} \times 1^{\circ}$ cells (bottom) in the Indian Ocean, based on the data reported for the purse seiner fleets with fleet codes "France", "Spain", "Mauritius", "Seychelles" and "Not elsewhere includedother". The dotted line represents linear regression to the data. $R^{2}=$ 0.32 (top) and $R^{2}=0.67$ (bottom).

\subsection{Base-simulation and MPA scenarios}

The model was run using three dimensional fields of physical and biogeochemical variables provided by climatological runs of the coupled bio-physical NEMO-PISCES model. The model therefore represented the annual dynamics of the skipjack population under mean environmental conditions and without the effect of interannual variability in oceanic conditions (e.g., ENSO events), or climate change. In order to account for the effect of the increase in commercial exploitation on the skipjack population, we started the simulation at the beginning of industrial fisheries. The first time period (1984-2010) was run to evaluate the effect of past exploitation on the present population. From there, we applied different scenarios and let the model run for 20 years (2011-2030) to explore the effect of different scenarios on the spawning population and catches.

The simulation of fisheries in the historical period was based on the parameters for fishing mortality and technological development, and on the approximation of the yearly exploited cells and the fishing effort outlined in the previous section. The spatial fishing effort was imposed using the algorithm that considered partial knowledge of the biomass distribution by the fishers, and no MPAs are considered in the historical period. The simulation of the future development of the population involved seven different scenarios that combined fishery scenarios with two different MPA configurations. Future exploitation trends were represented with three scenarios: the "worst case" scenario that considered the persistence of the linear increase of exploitation (fishing effort, fished cells and fishing power) obtained for the period 1984-2010; a moderate scenario that maintained the effort and number of explored cells at the level of 2010 but allowed the fishing power to increase at a 5\% rate;

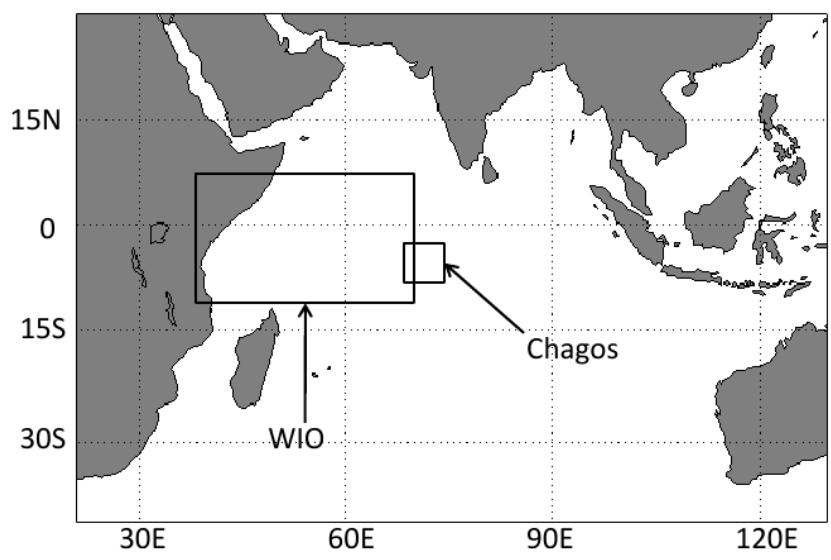

Fig. 2. Location of the MPAs used for the numerical experiment: hypothetical Western Indian Ocean -WIO MPA and Chagos MPA.

and a rather "positive" scenario where fisheries maintained the level of exploitation of 2010 including fishing power.

In the present study, we explored the effect of two very different MPAs: the Chagos Archipelago MPA, which has already been implemented, and a hypothetical Western Indian Ocean (WIO) MPA, covering a significant amount of the presently exploited area (Fig. 2). Unlike the Chagos MPA, the WIO MPA was purely hypothetical and its only purpose was to assess the effect of the closure of an area where the habitat is favourable to this species and where a great part of the fishing activities related to skipjack take place, in order to maximize the effect of this hypothetical MPA.

The seven scenarios can be summarized as: 1) Constant linear increase of exploitation: fishing power, effort, number of explored cells (worst case scenario); 2) Conditions of exploitation (effort and number of explored cells) maintained constant at the level of 2010, with increase of fishing power at 5\%;3) Condition of exploitation and technological development constant at the level of 2010; 4) Scenario 2 + Chagos MPA; 5) Scenario 2 + Western Indian Ocean MPA; 6) Scenario 3 + Chagos MPA; 7) Scenario 3 + Western Indian Ocean MPA.

\subsection{Formulation of density-dependent forage and impact on recruitment}

The relation between density dependent recruitment and population dynamics is central in ecology since it drives the response of a population to exploitation (Goodwin et al. 2006). The theory states that at high population sizes, density dependent processes reduce the number of recruits produced per spawner through competition for food. This process, usually represented by a stock recruitment curve, limits the population size when it is not exploited and gives the population a capacity to compensate for exploitation. Therefore, it is considered an essential factor to be included in stock assessment and the evaluation of stock management options. However, due to the high uncertainty associated with field measurements and the variability induced by environmental factors, density dependence is difficult to measure in wild populations (Rose et al. 2001).

In our model, the density-dependent recruitment is not defined by a stock recruitment curve, but density dependent access to forage is considered. With respect to previous 
applications of the APECOSM-E model, we improved the formulation of the density dependent forage $\hat{F}$ available to each predator of size $w$. We represented it by multiplying the available food $F(w)$ by a negative exponential:

$$
\hat{F}(w)=F(w) \cdot e^{-z}
$$

where $z$ is a coefficient that represents the predation undergone by prey organisms. The coefficient $z$ is inversely proportional to the available food, given by the forcing field, and directly proportional to the number of predators of size $w$ sharing the food, $n_{\text {pred }}$, and the food consumed by each predator, which is assumed proportional to the surface of the predator $V^{2 / 3}$ multiplied by a constant coefficient $a$ :

$$
z=\frac{n_{\text {pred }} V^{\frac{2}{3}} a}{F(w)}
$$

The coefficient $z$ can therefore vary between 0 (no predators) and $+\infty$ (very low concentration of food and/or very high number of predators), and consequently the value of the exponential varies between 1 and 0 .

\section{Results}

\subsection{Comparison of observed and simulated catch}

Simulated annual catches were compared with observed catches of purse seiners and bait boats from 1984 to 2010. Observed catches showed a high degree of yearly variability, determined by the interannual changes in the environmental conditions that affect population growth and catchability. Conversely, the simulation was run with a climatology of environmental forcing fields that excluded interannual variability; the simulated catches therefore show a steady trend. Nevertheless, the simulated and observed curves followed a similar trend with a steeper increase of catches in the first ten years, determined by the higher rate of technological development in this first period, followed by a smoother increase of catches in the subsequent period (1995-2010). The model simulated a rise of annual catches from around $110000 \mathrm{t}$ in 1984 to approximately $275000 \mathrm{t}$ in 2010 . This result compares well with the annual skipjack catches reported by purse seiners and baitboats for the same period (Fig. 3).

\subsection{Forecasted population dynamics and stock-recruitment curve}

For the historical time period 1984-2010, the model showed a decrease in the mean spawning biomass from 2.3 million tons to 1.6 million tons $(-30 \%)$ and an increase in catches from 110000 tons to 275000 tons $(+150 \%)$. This led to an increase of yearly fishing mortality from 0.05 to 0.17 $(+240 \%)$ (Fig. 4).

The three scenarios for the future development of fisheries without MPAs showed different trends. Similar responses in terms of catch, spawning biomass and mortality were found

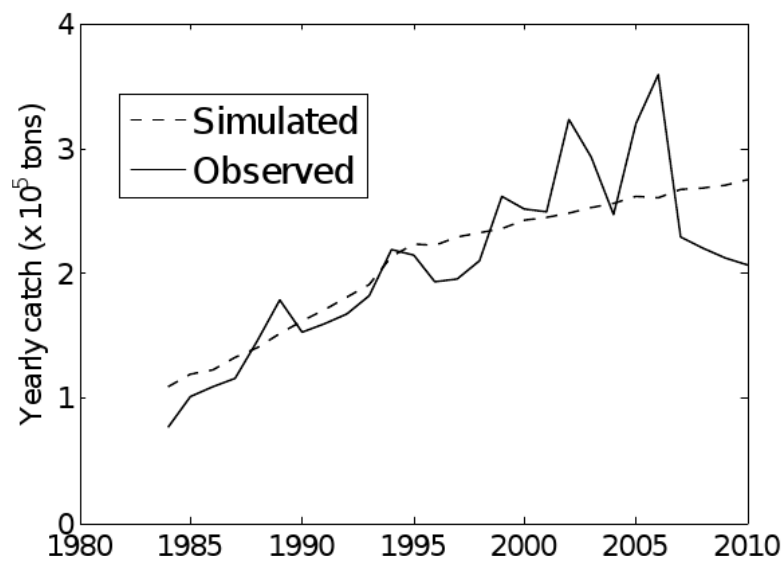

Fig. 3. Simulated (dots) and observed (line) trends of yearly catch of skipjack in the Indian Ocean. Observations consist of reported purse seine and baitboat catches.

for scenario 1 and scenario 2, while scenario 3 led to very different outcomes. Compared with the level of catches and mature population in 2010, predictions for 2030 made with scenario 1 and 2 gave a loss of $10 \%$ of catches and a loss of $40 \%$ of the spawning population $(-60 \%$ if we consider the population level of 1984), while scenario 3 predicted that in 2030 there would be a $17 \%$ loss in catches and a $19 \%$ loss in spawning population. This highlights that the trend of technological development plays a key role in the outcome of the simulation.

In general, the simulations showed a very minor impact of the Chagos MPA (scenarios 4 and 6) on the fishing mortality and annual catch, compared with the respective scenarios without MPAs (scenarios 2 and 3), resulting in a practically undetectable effect on the mean skipjack spawning population. With regards to the Western Indian Ocean MPA (scenarios 5 and 7), the model pointed out that the efficacy of this MPA would depend on the fishery exploitation scenario. Compared with the catches in 2010, a substantial effect of the WIO MPA was observed when the fishing effort and the number of exploited cells were stable and the technological development increased. The results of this scenario (No 5) show that the closure of the zone first induced a sudden decrease in catches. Then, the catches started to increase and, at the end of the simulation, were higher than in the simulation without an MPA. At the same time, there was a stabilization of the spawning population. With respect to the level of catches and spawning population in 2010 , if we consider scenario 5, the model predicts that in 2030 there will be an additional $8 \%$ loss in catches and a $10 \%$ loss in spawning population. Interestingly, the model predicts that the effect of the WIO MPA with a stabilization of technological development at the level of 2010 (scenario 7) would lead to a population level similar to scenario 5, but lower absolute catches (-20\% compared to 2010). These results highlight the importance of the fisheries scenarios on the effect of the MPA.

By simulating the population dynamics under a continuously increasing exploitation, we could calculate the stock recruitment relation by plotting monthly values of spawning biomass against recruitment (Fig. 5). Interestingly, the results showed a higher variability of recruitment at a high level of spawning biomass and this variability smoothly decreased 

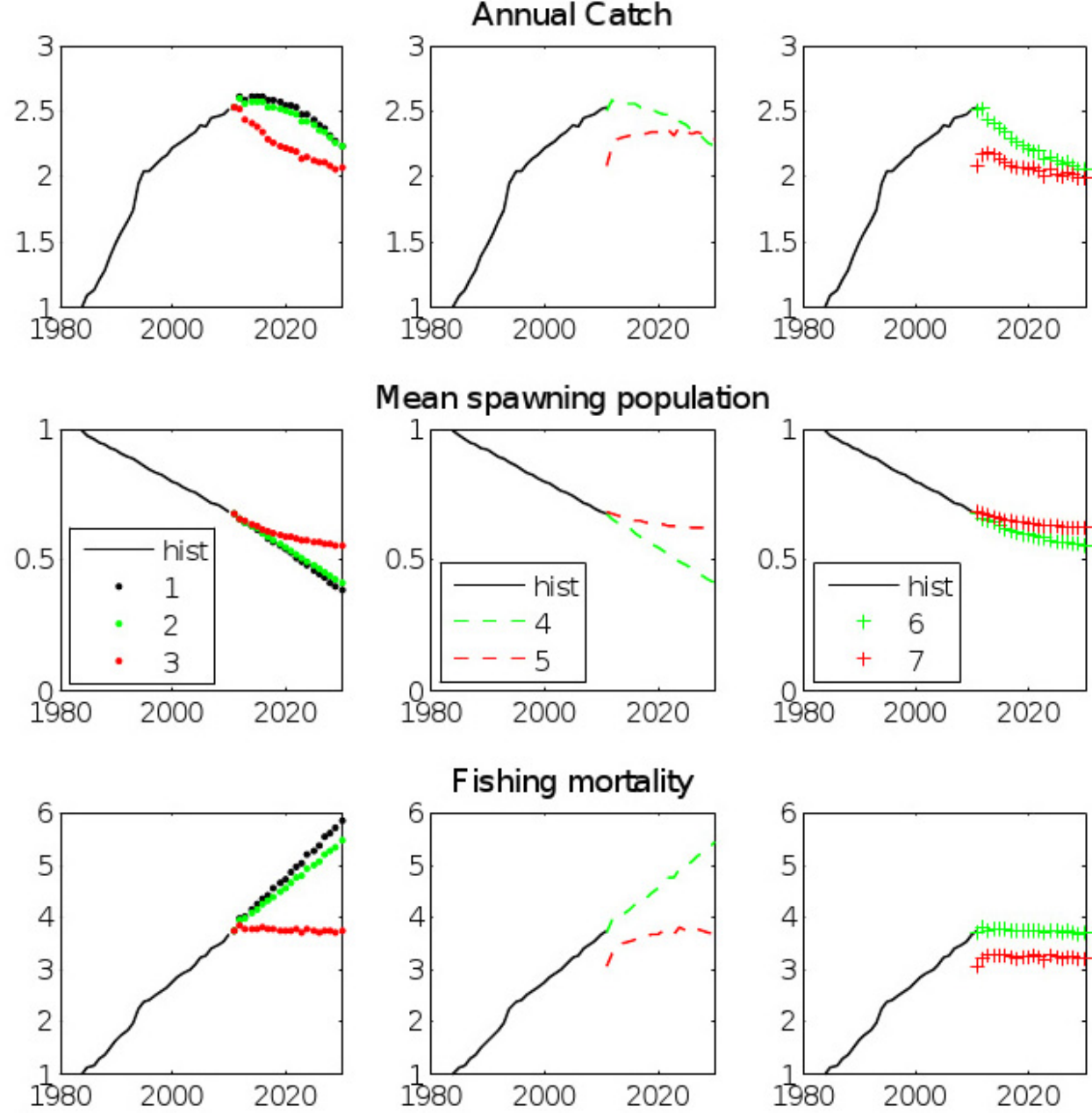

Fig. 4. Normalized annual catch (top), mean spawning population (middle) and fishing mortality (bottom) for the historical time period (1984-2010) and the 7 different scenarios (2011-2030) explored in the study. The first column shows results from the historical time period (hist) and scenarios without MPAs $(1,2$, and 3). The second column shows results from the historical time period and scenarios $4(2+$ Chagos) and $5(2+\mathrm{WIO})$. The third column shows results from historical time period and scenarios $6(3+\mathrm{Chagos})$ and $7(3+\mathrm{WIO})$.

when the population declined. The flattening or compensatory effect that is typically predicted for unexploited populations did not emerge clearly from the model results, as it was disguised by the effect of seasonally changing environmental conditions that affected the physiological rates. A closer look at the model outputs shows that the compensatory effect occured during the months where there was limitation of physiological rates due to low food availability but, during months without limitation (and therefore higher recruitment), the effect did not appear.

\section{Discussion}

Our model predicts minor and almost undetectable effect of the Chagos MPA on skipjack conservation and fisheries. This outcome contrasts with the statement of Koldewey et al. (2010) who suggested that the implementation of the Chagos no-take MPA should benefit large pelagic and migratory species such as tropical tunas, by attracting them around the island and retaining them for a significant amount of time due to the "island mass effect". Conversely, our simulations show a seasonal migration of skipjack tuna out of the Chagos MPA, as a result of seasonally-changing habitat conditions. Previous studies have shown that, if a population had a high rate of movement and individuals spent too much time outside of the reserve, the reserve could not provide sufficient protection (Botsford et al. 2003). Our simulations suggest that skipjack tuna is too mobile to benefit from the Chagos MPA.

According to our model results, the population would currently be at $60 \%$ of its initial population size (before industrial fisheries) and density-dependent processes would not compensate for its exploitation by fisheries. Given the many simplifying assumptions on which the model is based, the results of our numerical experiments should be interpreted cautiously. In fact, our assumptions are likely to underestimate the effect of exploitation and the model outcome can therefore be presumed to be too optimistic. Although the representation of fisheries relies on the reported catch/effort statistics of the main purse seine and baitboat fisheries, other artisanal fisheries (e.g., gillnet) are known to exploit the skipjack population. These fisheries are characterized by a high level of uncertainty, but their 


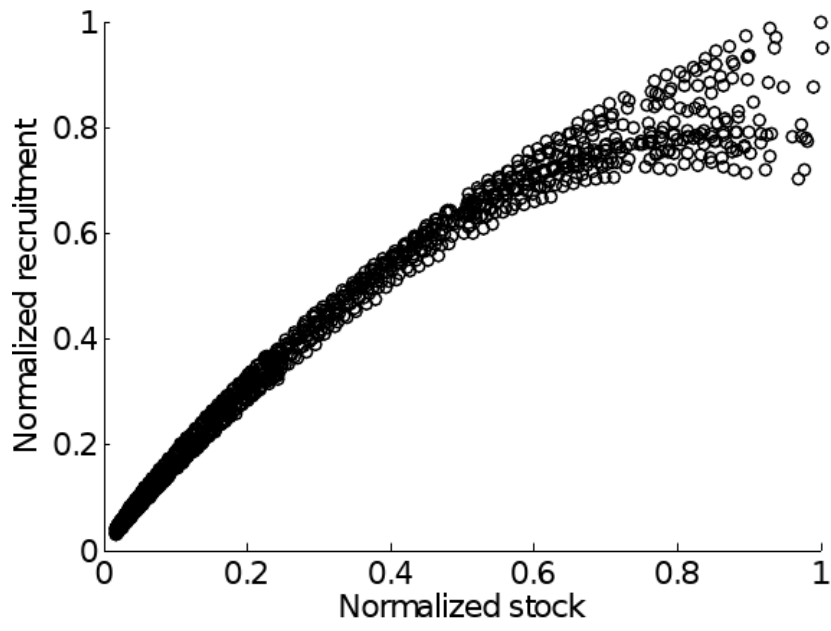

Fig. 5. Normalized stock recruitment curve that emerges from the model simulation under increasing exploitation. The dots represent average monthly values of the recruitment of fish $>30 \mathrm{~cm}$ as a function of spawning stock.

contribution is believed to be important and could account for an additional $30 \%$ of catches (IOTC 2010a). Therefore, we may be well beyond the exploitation level predicted by the model.

An important source of uncertainty and a limitation of the present study comes from the representation of the fishing fleets: the model does not consider the effect of the closure of the fishing zone on the fleets in terms of travel distance and fuel costs. Moreover it neglects to consider possible adaptation of the fishermen to the new conditions. These aspects have proven to be important (Salas and Gaertner 2004; Abbott and Haynie 2012) and could be included by adding a dynamic model of the fleet spatial behaviour, linked to the fishing costs and the prices of the fish. Several models that incorporate these effects are documented in the literature (Wilen et al. 2002; Grafton et al. 2005; Dowling et al. 2011), but in order to better anticipate the possible re-allocation of effort in response the implementation of an MPA, we need first to deepen our understanding of fisher behaviour (Salas and Gaertner 2004; Torres-Irineo et al. 2011; Abbott and Haynie 2012).

\section{Conclusion and perspectives}

The outcome of our study highlighted the crucial importance of fisheries scenarios for the evaluation of the long term impact of MPAs. The model showed that the effect of an MPA strongly depends on the evolution of fishing effort and efficiency of fishing vessels (technological development). These results pointed out that fishery regulations, as well as socioeconomic factors driving fleet dynamics and efficiency, were key elements when considering the long term impact of spatial conservation measures, and that these factors should be carefully considered when exploring different management options. This finding can presumably be extended from skipjack tuna to other highly exploited pelagic species with similar mobility characteristics.
Spatially-explicit population dynamics models -that account for the impact of fisheries and include the effect of environmental variability- are new and powerful tools (Lehodey et al. 2008; Dueri et al. 2012a). They can provide information to help fishery management in taking decisions, since they allow modelling experiments that provide important insights for the understanding of a population and its response to different scenarios. However, models are simplified representations of a complex reality, and oversimplified interactions can reduce the ability of the model to represent the dynamics of the system and compromise the reliability of a forecast. In the present model, fisheries and their future evolution are described in a very simplified manner, and model performance could be considerably enhanced by increasing the effort towards understanding fleet behaviour and integrating it into the model structure.

Acknowledgements. This work was supported both by the AMPED project (www.amped.ird.fr) through a grant from the French National Research Agency (ANR), Systerra Programme, grant number ANR08-STRA-03 and by the MACROES project (http://www.macroes. ird.fr/) through a grant from the French National Research Agency (ANR), CEP Programme, grant number ANR-09-CEP-003. It is a contribution to the CLIOTOP WG4. The fisheries data presented in this publication were obtained from the IOTC (http://www.iotc.org) through the CLIOTOP-MDST portal. We wish to acknowledge the contribution of the staff of the "Observatoire Thonier" of the Mixed Research Unit 212 "Exploited Marine Ecosystems" (IRD) for data processing and management.

\section{References}

Abbott J.K., Haynie A.C., 2012, What are we protecting? Fisher behaviour and the unintended consequences of spatial closures as fishery management tool. Ecol. Appl. 22, 762-777.

Adam M.S., 2010, Declining catches of skipjack in the Indian Ocean - Observation from the Maldives. Proc. 10th Meeting of the working party on tropical tuna, Indian Ocean Tuna Commission, IOTC-2010-WPTT-09.

Aumont O., Bopp L., 2006, Globalizing results from ocean in situ iron fertilization studies. Glob. Biogeochem. Cycles 20, GB2017, doi:10.1029/2005GB002591.

Barkley R., Neill W.H., Gooding R.M.G., 1978, Skipjack tuna, Katsuwonus Pelamis, habitat based on temperature and oxygen requirements. Fish. Bull. 76, 653-662.

Botsford L.W., Micheli F., Hastings A., 2003, Principles for the design of marine reserves. Ecol. Appl. 13, S25-S31.

Brill R.W., 1994, A review of temperature and oxygen tolerance studies of tunas pertinent to fisheries oceanography, movement models and stock assessments. Fish. Oceanogr. 3, 204-216.

Brill R.W., Lutcavage M.E., 2001, Understanding environmental influences on movements and depth distributions of tunas and billfishes can significantly improve population assessment. Am. Fish. Soc. Symp. 25, 179-198.

Dowling N.A., Wilcox C., Mangel M., Pascoe S., 2011, Assessing opportunity and relocation costs of marine protected areas using a behavioral model of longline fleet dynamics. Fish Fish. 13, 139-157.

Dueri S., Faugeras B., Maury O., 2012a, Modelling the skipjack tuna dynamics in the Indian Ocean with APECOSM-E: Part 1 Model formulation. Ecol. Model. 245, 41-54. 
Dueri S., Faugeras B., Maury O., 2012b, Modelling the skipjack tuna dynamics in the Indian Ocean with APECOSM-E: Part 2 Parameter estimation and sensitivity analysis. Ecol. Model. 245, 55-64.

Faugeras B., Maury O., 2007, Modeling fish population movements: From an individual-based representation to an advectiondiffusion equation. J. Theor. Biol. 247, 837-848.

Game E.T., Grantham H.S., Hobday A.J., Pressey R., Lombard A.T., Beckley L..E., Gjerde K., Bustamante R., Possingham H.P., Richardson A.J., 2009, Pelagic protected areas: the missing dimension in ocean conservation. Trends Ecol. Evol. 24, 360-369.

Grafton R.Q., Kompas, T., Lindenmayer D., 2005, Marine reserves with ecological uncertainty. Bull. Math. Biol. 67, 957-971.

Grüss A., Kaplan D.M., Guénette S., Roberts C.M., Botsford L.W., 2011, Consequences of adult and juvenile movement for marine protected areas. Biol. Conserv. 144, 692-702.

Goodwin N.B., Grant A., Perry A.L., Dulvy N.K., Reynolds J.D., 2006, Life history correlates of density-dependent recruitment in marine fishes. Can. J. Fish. Aquat. Sci. 63, 494-509.

Hobday A.J., Hartmann K., 2006, Near real-time spatial management based on habitat predictions for a longline bycatch species. Fish. Manage. Ecol. 13, 365-380.

Hobday A.J., Hartog J.R., Spillman C.M., Alves,O., 2011, Seasonal forecasting of tuna habitat for dynamic spatial management. Can. J. Fish. Aquat. Sci. 68, 898-911.

Hyrenbach K.D., Forney K.A., Dayton P.K., 2000, Marine protected areas and ocean basin management. Aquat. Conserv. Mar. Freshw. Ecosyst. 10, 437-458.

Indian Ocean Tuna Commission, 2008, Report of the First Session of the IOTC Working party on tagging data analysis. Victoria, Seychelles IOTC-2008-WPTDA-R[E].

Indian Ocean Tuna Commission, 2010a, Report of the twelfth session of the IOTC Working party on tropical tunas. Victoria, Seychelles, IOTC-2010-WPTT-R[E].

Indian Ocean Tuna Commission, 2010b, For the conservation and management of tropical tunas stocks in the IOTC area of competence. IOTC resolution 10/01, Indian Ocean Tuna Commission.

Koldewey H.J., Curnick D., Harding S., Harrison L.R., Gollock M., 2010, Potential benefits to fisheries and biodiversity of the Chagos Archipelago/British Indian Ocean Territory as a no-take marine reserve. Mar. Pollut. Bull. 60, 1906-1915.

Kooijman S.A.L.M., 2000, Dynamic energy and mass budgets in biological systems. Cambridge University Press.

Lehodey, P., Senina, I., Murtugudde, R. 2008, A spatial ecosystem and population dynamics model (SEAPODYM) - Modeling of tuna and tuna-like populations. Prog. Oceanogr. 78, 304-318.

Lester S.E., Halpern B.S., Grourud-Covert K., Lubchenco J., Ruttenberg B.I., Gaines,S.D., Airamé S., Warner R.R., 2009, Biological effects within no-take marine reerves: a global synthesis. Mar. Ecol. Prog. Ser. 384, 33-46.

Marine Research Centre, Maldives, 1996, The Maldivian tuna fishery: a collection of tuna resource papers. Maldives Mar. Res. Bull. 2.

Marsac F., Le Blanc J.L., 1998, Interannual and ENSO-associated variability of the coupled ocean-atmosphere system with possible impacts on the yellowfin tuna fisheries in the Indian and Atlantic oceans. In: ICCAT Tuna Symposium, ICCAT Coll. Vol. Sci. Pap. L(1), 345-377.

Maury O., 2010, An overview of APECOSM, a spatialized mass balanced "apex predators ecosystem model" to study physiologically structured tuna population dynamics in their ecosystem. In: St John M.A., Ruiz J., Monfray P. (Eds.) Parameterisation of trophic interactions in ecosystem modelling. Prog. Oceanogr. 84, 113-117.
Maury O., Gascuel D., 1999, SHADIS ("simulateur halieutique de dynamiques spatiales"), a GIS based numerical model of fisheries. Example application: the study of a marine protected area. Aquat. Living Resour. 12, 77-88.

Maury O., Nordström V., 2002, Application of the PROCEAN model to the Indian ocean yellowfin tuna (Thunnus albacores) fishery. IOTC working party on tropical tuna, Shangai 3-11/06/2002.

Ménard F., Marsac F., Bellier E., Cazelles B., 2007, Climatic oscillations and tuna catch rates in the Indian Ocean: a wavelet approach to time series analysis. Fish. Oceanogr. 16, 95-104.

Moffitt E.A., Botsford L.W., Kaplan D.M., O'Farrell M.R., 2009, Marine reserve networks for species that move within a home range. Ecol. Appl. 19, 1835-1847.

Mugo R., Saitoh S.I., Nihira A., Kuroyama T., 2010, Habitat characteristics of skipjack tuna (Katsuwonus pelamis) in the western North Pacific: a remote sensing perspective. Fish. Oceanogr. 19, 382-396.

Pitcher T.J., 2001, Fisheries managed to rebuild ecosystems? Recostructing the past to salvage the future. Ecol. Appl. 11, 601-617.

Roberts C.M., Bohnsack,J.A., Gell F., Hawkins J.P., Goodridge R., 2001, Effects of marine reserves on adjacent fisheries. Science 294, 1920-1923.

Roberts C.M., Hawkins J.P., Gell F.R., 2005, The role of marine reserves in achieving sustainable fisheries. Phil. Trans. R. Soc. B $360,123-132$.

Rose K.A., Cowan J.H. Jr., Winemiller K.O., Myers R.A., Hilborn R., 2001, Compensatory density dependence in fish populations : importance, controversy, understanding and prognosis. Fish Fish. 2, 293-327.

Salas S., Gaertner D.,2004, The behavioral dynamics of fishers: management implications. Fish Fish. 5, 153-167.

Stéquert B., Ramcharrun B., 1996, La reproduction du listao (Katsuwonus pelamis) dans le bassin ouest de l'océan Indien. Aquat. Living Resour. 9, 235-247.

Sumaila U.R., Guénette S., Alder J., Chuenpagdee R., 2000, Addressing ecosystem effects of fishing using marine protected areas. ICES J. Mar. Sci. 57, 752-760.

Torres-Irineo E., Gaertner D., Delgado de Molina A., Ariz J., 2011, Effect of time-area closure on tropical tuna purse-seine fleet dynamics through some fishery indicators. Aquat. Living Resour. 24, 337-350.

UNOSAT 2009, Analysis of Somali pirate activity in 2009. Available: http://unosat.web.cern.ch/unosat/freeproducts/ somalia/Piracy/2009/UNOSAT_Somalia_Pirates_Analysis_Q1_ 2009_23April09_v1.pdf.

Valdemarsen J.W., 2001, Technological trend in capture fisheries. Ocean Coast. Manage. 44, 635-651.

Walters C., 2000, Impacts of dispersal, ecological interactions, and fishing effort dynamics on efficacy of marine protected areas: how large should protected areas be? Bull. Mar. Sci. 66, 745-757.

Walters C.J., Hilborn R., Parrish R., 2007, An equilibrium model for predicting the efficacy of marine protected areas in coastal environments. Can. J. Fish. Aquat. Sci. 64, 1009-1018.

Wilcox C., Pomeroy C., 2003, Do commercial fishers aggregate around marine reserves? Evidence from Big Creek marine ecological reserve, Central California. N. Am. J. Fish. Manage. 23, 241-250.

Wilen J.E., Smith M.D., Lockwood D., Botsford L.W., 2002, Avoiding surprises: incorporating fisherman behavior into management models. Bull. Mar. Sci. 70, 553-575. 